\title{
Growth effectivity of molds in contact with methylxanthines
}

\author{
Klára Kobetičová ${ }^{1, *}$, Václav Kočí ${ }^{1}$, Michaela Petř́ḱková $^{1}$, Kristýna Šimůnková ${ }^{2}$, and Robert \\ Černý $^{1}$ \\ ${ }^{1}$ Department of Materials Engineering and Chemistry, Faculty of Civil Engineering, Czech Technical \\ University in Prague, Thákurova 7/2077, 16629 Prague 6, Czech Republic \\ ${ }^{2}$ Department of Wood Processing and Biomaterials, Faculty of Forestry and Wood Sciences, Czech \\ University of Life Sciences Prague, Kamýcká 126, 16500 Prague, Czech Republic
}

\begin{abstract}
Molds on buildings can cause health- and aesthetic problems. Looking for suitable cheap and non-toxic substances to eliminate them is therefore an actual task. In the present study, effect of three selected methylxanthines (1,3,7-trimethylpurine-2,6-dione, 3,7-dihydro-3,7dimethyl-1H-purine-2,6-dione and 1,3-dimethylxanthine) on growth of non-specific species of molds occurring on building materials were tested on agar medium under laboratory conditions. The chemical substances were dissolved in distilled water and applied into agar. Solid agar has been exposed to air molds for 24 hours. Agar plates were then covered with lids and placed for 5 days in a laboratory thermostat at stable test conditions (dark place, $25{ }^{0} \mathrm{C}$ ). After that, the mycelium was observed. The results showed that 3,7-dihydro-3,7-dimethyl- $1 \mathrm{H}$-purine-2,6-dione and 1,3dimethylxanthine were not effective against the molds growth. On the other hand, 1,3,7-trimethylpurine-2,6-dione was able to eliminate mold growth on agar medium at a concentration of $1 \mathrm{~g} \cdot \mathrm{l}^{-1}$ or higher.
\end{abstract}

\section{Introduction}

Wood as a natural renewable resource plays an important role in the construction industry. Wood can be attacked by various fungi and molds. While fungi are able to decompose lignin or cellulose in wood in depth, molds can be found on a cover of wood and thus can cause unpleasant coloring of timber. Therefore, constructional timber has to be painted by some protecting mixtures. Presently, original chemical protective preparations containing metals or persistent organic substances are gradually banned for their toxicity, persistency and bioaccumulative potential [1-2]. Plant extracts or extraction of some biologically active substances seem to be therefore suitable substitutes. The most spread and effective natural biocides contain extracts from trees as bark sources of plant oils (either vegetal oils or essential oils), flax seeds [3], cinnamon [4-5], citrus peels [6], and tung seeds. They have been experimented with as potential wood protectors, showing diverse activities as antibacterial, antifungal and antiinsect agents [7-10].

\footnotetext{
${ }^{*}$ Corresponding author: klara.kobeticova@fssv.cvut.cz
} 
In the present study, methylxanthines were selected as model substances. They belong to a group of phytochemicals derived from the purine base xanthine obtained from plant metabolism [11-12]. The most known substances are 3,7-dihydro-3,7-dimethyl-1H-purine2,6-dione (theophyline), 1,3-dimethylxanthine (theobromine) and 3,7-trimethylpurine-2,6dione (caffeine). They were also selected for this research, being commonly found in coffee, tea and cocoa. All of the selected substances are white and crystalline with variable solubility in water. Some plants can produce them as natural metabolites for their own protection against insects [13]. Effectivity of caffeine was tested against fungi and molds in the past [14-15] but theobromine and theophyline have not been tested yet. Therefore, we tested the effectiveness of water concentrations of these three selected methylxanthines against aerial molds.

\section{Materials and methods}

The studied methylxanthines were theophyline, theobromine, and caffeine. They were purchased from Sigma Aldrich, Ltd., Czech Republic. The most soluble concentration of selected methylxanthines was used in the preliminary experiment. The basic properties of studied substances are described in Table 1.

Table 1. Formula, structural formula, molar weight $\left(\mathrm{g} \cdot \mathrm{mol}^{-1}\right)$ and solubility in water $\left(\mathrm{g} \cdot \mathrm{l}^{-1}\right)$ at $20{ }^{0} \mathrm{C}$ of studied substances.

\begin{tabular}{|c|c|c|c|c|}
\hline Substance & Formula & Structural formula & Molar weight & Solubility in water \\
\hline Caffeine & $\mathrm{C}_{8} \mathrm{H}_{10} \mathrm{~N}_{4} \mathrm{O}_{2}$ & & 194.19 & 20 \\
\hline Theobromine & $\mathrm{C}_{7} \mathrm{H}_{8} \mathrm{~N}_{4} \mathrm{O}_{2}$ & & 180.16 & 0.330 \\
\hline Theophyline & $\mathrm{C}_{7} \mathrm{H}_{8} \mathrm{~N}_{4} \mathrm{O}_{2}$ & & 180.16 & 5.5 \\
\hline
\end{tabular}

The appropriate amount of substance powder was dissolved in sterile 3\% maltose agar (P-Lab, Ltd., Czech Republic) and filled into Petri glass $(\mathrm{d}=9 \mathrm{~cm})$. Three replicates were prepared for each substance and for control (clear agar without tested substances). One replicate containing each tested substance was also used as a control of substance- and agar purity and sterility during the test period. The Petri dishes with cool agar were placed for fall of mold spores from air for 2 hours. After that, the Petri dishes were covered by Petri lids, packaged into aluminum foil and stored in a biological incubator for 5 days under 
controlled test conditions (in dark, temperature $25{ }^{\circ} \mathrm{C}$ ). At the end of the incubation period, the growth of mold mycelium was observed visually or under stereomicroscope (Olympus) in all Petri dishes. The basic experiment was performed by the same methodology but only caffeine was tested, taking into account the results of the preliminary experiment. The concentration range was $0,0.0625,0.125,0.25,0.5,1,5,10,15,20 \mathrm{~g} \cdot 1^{-1}$, on the basis of results of the first experiment. The final experiment was designed according to the results of the basic experiment and the tested concentrations of caffeine were $0,1,2,3,4$ and $5 \mathrm{~g} \cdot 1^{1}$.

\section{Results and discussion}

The results of the preliminary test indicated that theophyline and theobromine did not have any effect on the growth of mold mycelium (Fig. 1). Therefore, the basic experiment was performed with caffeine only. The results of basic experiment showed that caffeine had $100 \%$ inhibition effect for concentrations $1 \mathrm{~g} \cdot \mathrm{l}^{-1}$ and higher. Concentrations in the range of 0.12 to $0.5 \mathrm{~g} \cdot \mathrm{l}^{-1}$ caused certain growth of molds. Hence, the final experiment was realized using the concentration range of 1 to $5 \mathrm{~g} \cdot \mathrm{l}^{-1}$. In this experiment, it was observed that caffeine caused $100 \%$ inhibition of mold mycelium at all tested concentrations (Fig. 2).

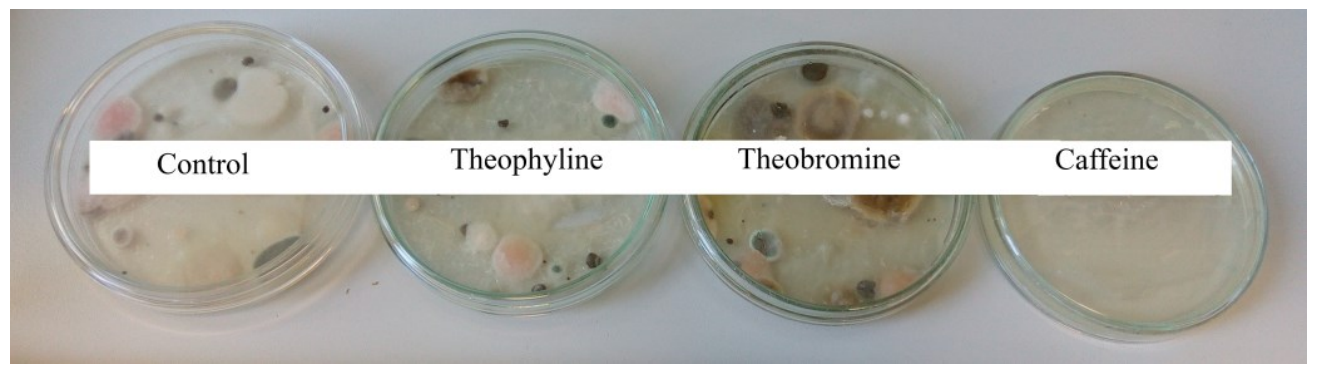

Fig. 1. Illustration of mold growth exposed to tested methyxanthines.

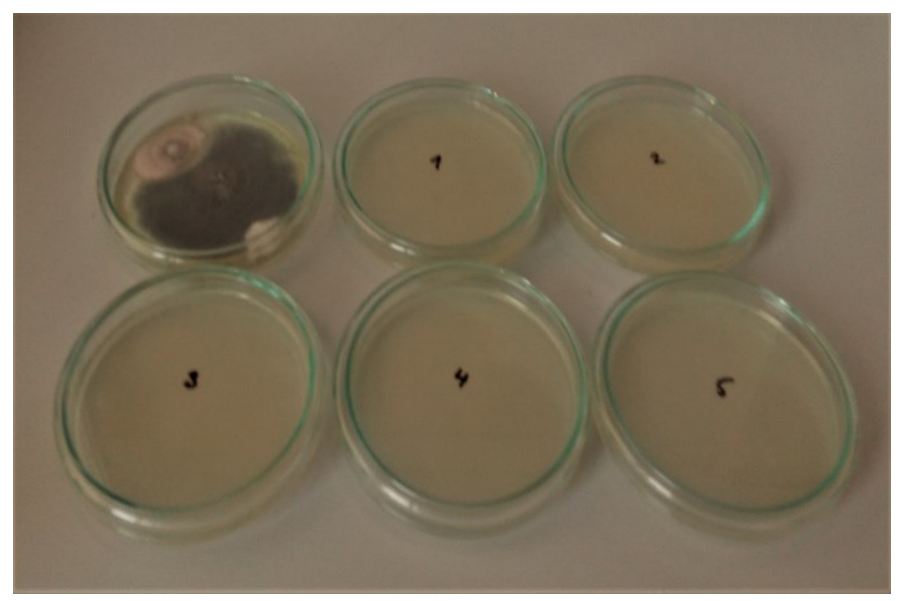

Fig. 2. The experiment with caffeine - growth of mold mycelium exposed to control agar without caffeine $(=0)$ and the concentration $1,2,3,4,5 \mathrm{~g} \cdot \mathrm{l}^{-1}$. 
The mold growth expressed as resistance (in \%) against caffeine is summarized in Fig. 3. This calculation was modified for agar medium, contrary to the original use for wood materials [16]. The growth of molds had the same resistance for the individual concentrations. So, the Fig. 3 does not include error bars for individual columns.

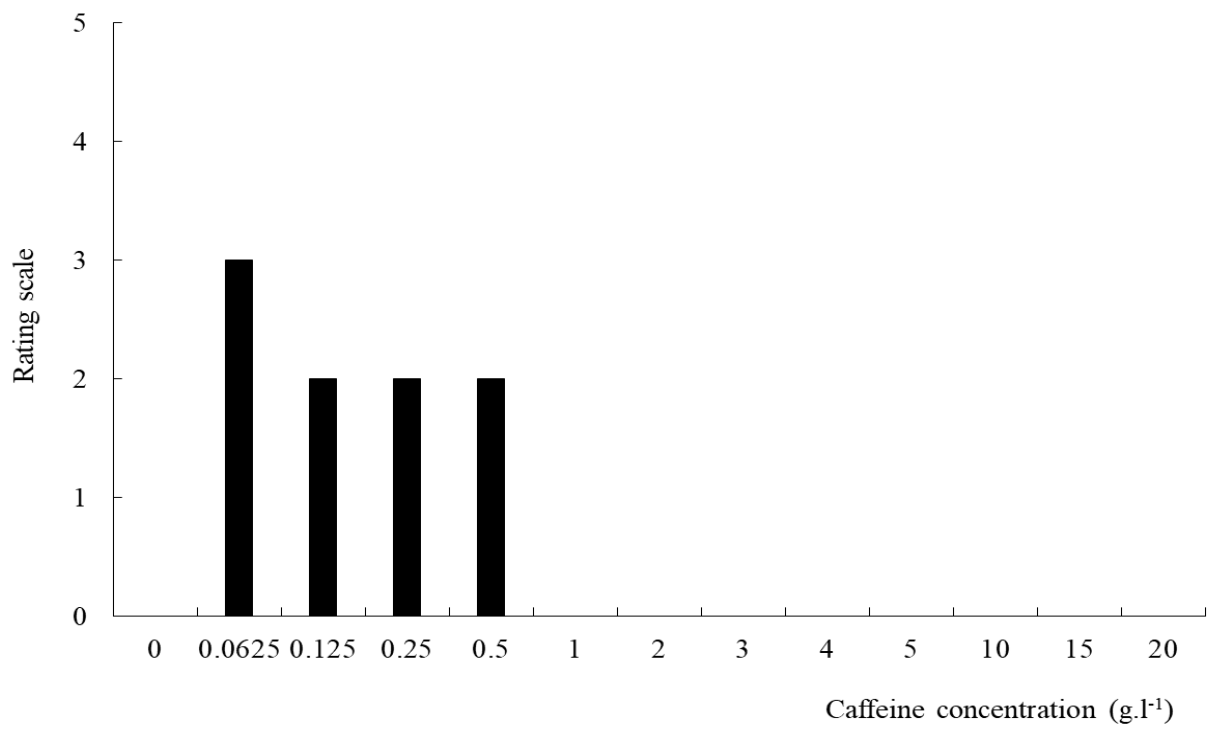

Fig. 3. Average mold resistance rating for agar containing caffeine. Mold resistance rating scale: 0 - no visible growth under the stereomicroscope, 1 - growth invisible by eyes, but clearly visible under the stereomicroscope, 2 - coverage of up to $25 \%$ of the agar dish, 3 - coverage of up to $50 \%$ of the agar dish, 4 - coverage of more than $50 \%$ of the agar dish 5 - intensive growth covering the agar dish.

\section{Conclusions}

In the present study, agar tests with aerial unspecific molds exposed to three selected methylxanthines, namely caffeine, theobromine and theophyline, were performed. Both degradation products of caffeine (theobromine and theophyline) did not affect the growth ability of molds but caffeine totally inhibited mold mycelium on agar medium at the concentrations higher than $1 \mathrm{~g} \cdot \mathrm{l}^{-1}$. Therefore, further work will be focused on the use of caffeine against selected mold species on various constructional timbers.

This research has been supported by the Czech Science Foundation under Project No. 19-02067S.

\section{References}

1. Y. Liu, J. Du., Z. Dong, M.M. Rahman, Y. Gao, K. Yan, Kaihong, R. Naidu, Chemosphere 216, 757 (2019)

2. A. Pizzi, Holzforschung 47, 253 (1993)

3. E.E. Mastalygina, A.A. Popov, P.V. Pantyukhov, IOP Conference Series-Materials Science and Engineering, UNSP 012011 (2017)

4. $\quad$ S.Y. Wang, P.F. Chen, S.T. Chang, Bioresour. Technol. 96, 813 (2005) 
5. S. Bardage, M. Westin, H.A. Fogarty, S. Trey, Int. Biodetr. Biodegr. 86, 54 (2014)

6. V.P. Gouw, J. Jung, J. Simonsen, Y. Zhao, Compos Part A, APPl. Sci. Manuf. 99, 48 (2017)

7. B.S. Higbee, C.O. Calkins, C.A. Temple, J. Econ. Entomol. 94, 1511 (2001)

8. G.A. Adedeji, O.Y. Ogunsanwo, T.O. Elufioye, Int. Biodetr. Biodegr. 116, 155 (2017)

9. R.F. Gonzalez-Laredo, M. Rosales-Castro, N.E. Rocha-Guzman, J.A. GallegosInfante, M.R. Moreno-Jimenez, J.J. Karchesy, Madera Bosques 21, 63 (2015)

10. I. Boulogne, P. Petit, H. Ozier-Lafontaine, L. Desfontaines, G. Loranger-Merciris, Environ. Chem. Lett. 10, 325 (2012)

11. R.G. Hollingsworth, J.W. Armstrong, E. Campbell, Nature 417, 915 (2002)

12. P.M. Frischknecht, J. Ulmer-Dufek, T.W. Baumann, Phytochem. 25, 613 (1986)

13. H. Ashihara, T. Suzuki, Front. Biosci. 9, 1864 (2004)

14. P. Kwasniewska-Sip, G. Cofta, P.B. Nowak, Int. Biodetr. Biodegr. 132, 178 (2018)

15. D.S. Arora, D. Ohlan, J. Basic Microbiol. 37, 159 (1997)

16. ISO EN 846. Plastics. Evaluation of the Action of Microorganisms (1997)

17. Vicencio, Ch. Andrade, A. Casadevall, D.L. Goldman, Mycopathologia 173, 83 (2012)

18. L.G. Baker, C.A. Specht, M.J. Donlin, J.K. Lodge. Eukaryot. Cell 6, 855 (2007) 